\title{
Reciprocal Reading Techniques as Part of the Metacognitive Comprehension: Special Implication for Second Year Students
}

\author{
Sawsan M.A. Ahmed ${ }^{1}$ \\ ${ }^{1}$ Taif University, Kingdom of Saudi Arabia \\ Correspondence: Sawsan M.A. Ahmed, Taif University, Kingdom of Saudi Arabia. E-mail: \\ sawsanaminahmed@gmail.com \\ Received: November 5, 2013 \\ Accepted: November 20, 2013 \\ Online Published: November 26, 2013 \\ doi:10.5430/elr.v2n2p60 \\ URL: http://dx.doi.org/10.5430/elr.v2n2p60
}

\begin{abstract}
Reading for academic reasons is a field that has not been explored often by researchers. In this research thirty-two college students are introduced to four techniques that are often indicated to increase comprehension as part of the metacgnitive method of reading. The four techniques are part of the method known as the reciprocal reading comprehension. A pretest is given with a specific number of points to ensure the homogeneity of the participants. Further, the students were asked to read and then answer questions related to the reading to see if the reading was done with comprehension. Then the students were introduced to the techniques. In subsequent weeks they were given texts to read and questions to answer implementing the newly taught techniques which comprise predicting, questioning, summarizing and clarifying. Improvement is detected at the end of the treatment.
\end{abstract}

Keywords: Reading techniques, Reciprocal reading, College reading

\section{Introduction}

Reading calls for fast, automatic word decoding and access to the mental (dictionary) i.e. the number of lexical items that are in existence in the brain. This means working on building speed and fluency is a lengthy process a part of which researchers emphasize learning to decode vocabulary words in the new language. Learners can build speed and fluency by learning to apply certain techniques. That can be achieved by doing extensive reading. Another important step is that learners can be versed on ways to purposely and consciously handle a variety of strategies to get the required meaning from texts. Learning to read as a strategy is of interest because they reveal how readers interact with written texts, also it shows how readers use a variety of strategies that result in effective reading comprehension.

\subsection{Historical Background}

Reading research began to focus on reading strategies in the late 1970s. The early studies, especially case studies that contain descriptive investigations that used the used think-aloud techniques and diary keeping tracking the mental processes that goes into reading. These early studies also identified the core relationships between certain types of reading strategies and the difference between successful and unsuccessful reading. In order to understand how learners tackle reading, researchers should first establish how readers process texts at a cognitive level. To get a clear idea of how learners comprehend reading texts depending on parallel 'top-down' and 'bottom-up' processing, the two processes were studied thoroughly.

The first method of the bottom-up processing in reading is found where the learner making a connection between letters with their sounds in a specified sequence. Language accordingly is viewed as a code and the reader decoders those symbols in a passive way. The reader's main task is to identify graphemes changing them into phonemes. Kucer (1987) identified the linearity of the process whereby readers decode a text, linking the words into a process made up of phases starting in phrases and then sentences. Samuels and Kamil (1988) placed the emphasis on "behaviorism" which treated reading as a word-recognition response to the stimuli of the printed words, where "little attempt was made to explain what went on within the recesses of the mind that allowed the human to make sense of the printed page" (25). Textual comprehension involves matching the meanings of words to get the meanings of clauses (Anderson 1994). This lower level of the decoding skills is associated with the visual stimulus. The only interaction between the reader and the text is what linguists call the building blocks of sounds and words. Reading activities are based on recognition which is done simultaneously with the recall of "lexical and grammatical" forms. The "bottom up" approach stipulates that the meaning of any text must be "decoded" by the reader and that learners are "reading" when they can "sound out" 
words from the reading text. It emphasizes the ability to de-code or put into sound what is seen in a text. It does not take into account assisting readers to recognize what they bring to the information on the page i.e. their past experiences. One of the drawbacks of the aforementioned model is the fact that it is difficult to account for syntax-context effects and the role of prior knowledge of text topic as a facilitating variable in word recognition and comprehension. Eskey (1973) described the decoding model and within that description the attention on the contribution of the reader who makes a guess about the text was underplayed. Guesses that readers make about the texts will help in processing information. The description fails to recognize that "students utilize their expectations about the text, based on their knowledge of language and how it works" (3).

The Top-down reading models were created by Gough in 1972 who pointed out that the reading is considered a Psycholinguistic Guessing Game. This theory replaced the 'bottom-up' models in which the reader tackles letters, words, and sentences. Top-down models meant that the reader deals with the text using past experiences. The "top down" approach emphasizes readers bringing meaning to text based on their experiential background and interpreting texts on the bases of their knowledge.

\subsection{Kinds of skills needed for reading}

Reading for a gist, skimming or looking for specific information, requires a different set of skills than that required for reading to get general information or to read for pleasure. Urquhart and Weir (1998) indicated that "Intensive reading, critical reading or reading to learn" will require yet a different balance between the two processes (45-46). All aspects of the processes are critical for gaining automaticity in reading.

\section{Metacognition}

John Favell (1976) and Brown (1978) explored the early work on metacognition. Their work provided an understanding of the learners' reflective processes and gave insights into the ways in which readers' knowledge about their cognition impacted their self regulation in different aspects of their reading. In spite of all the different theoretical aspects from the earliest frameworks, a common understanding of the metacognitive method have emerged is that it consisted of two components: knowledge about cognition and the regulation of cognition. The reader's knowledge about cognition refers to metaconitive knowledge Favell called self-knowledge of the aspects the task and knowledge of the strategy in use. Self regulation refers to the actions used to achieve and the reader's goals in learning.

Different methods of instruction that included the element of the metacognition have appeared since that time some of which are: Informed Strategies for Learning, Reciprocal Teaching, The Direct Explanation of Strategies, Transactional Strategies Instruction, Concept Orientated Reading Instruction, Collaborative Strategic Reading and Peer Assisted Learning Strategies. All of those methods have used the metacognitive theory as the base for creating methods of instruction in their implementation.

\subsection{Reciprocal teaching of comprehension}

The reciprocal teaching of reading concentrates on the use of techniques that can be applied to comprehend texts. Those are predicting, questioning, summarizing and clarifying. Instructions are involving the teacher explaining and modeling the strategies then, the students create a dimension about how, when and why these strategies should be implemented; and overtime the teacher guides and supports the students in applying the strategies. Ultimately, more responsibility is given to the students with them acting as the teacher as they develop the abilities to perform the strategy (Palicnser and Brown, 1984). Comprehension is also influenced by the degree of relation between the readers' prior knowledge and the content of the text. Multiple studies have demonstrated the influence of schematic constructive processes in text comprehension. This method comprises the use of four components which are predicting, questioning, summarizing and clarifying. The instructor begins by demonstrating applying the four skills while reading a text. Consequently, he asks the learners to take that role in applying the four techniques themselves.

\section{The research question}

Students who are taught techniques of the reciprocal reading, they will read faster and more efficiently and with increased comprehension than students who were not taught those techniques.

The dependent variable is regular or reduced reading comprehension, while the independent variable is the increased level of comprehension.

\subsection{Implementing the treatment}

The method that is used to implement the reciprocal comprehension related to the metacognitive way of comprehending reading texts followed the method indicated in the four pinnacles of the method which is predicting, 
questioning, summarizing and clarifying with the core of the method of the teacher demonstrating the skills and in time allowing the students to conduct the skills themselves. At first the researcher modeled the four techniques of predicting, questioning, summarizing, and clarifying. Then, lead students were assigned the roles of predictor, questioner, summarizer, and clarifier. Students then are instructed to read a few paragraphs of assigned texts selection while encouraged to use note-taking strategies such as selective underlining or highlighting to help them prepare for their role in the discussion. The summarizer will highlight the key ideas up to this point in the reading. The questioner will then pose questions about the selection: of why the title is given as well as why certain headings are provided, how the author poses a question. The clarifier is the asked to discuss unclear or confusing parts and attempt to answer the questions that were just posed. The predictor can make predictions about what the text suggests as to what the author will discuss next. If the text is a literary selection, the predictor might offer a suggestion as to what the next events in the selection will be. The roles in the group then switch from one person to the next. Students alternate the roles using new roles. The groups were scored on the improvement they have shown while responding to the reading tests and when asked to do the reading tests by themselves. Regarding the final tests where scores were collected.

\subsection{Materials}

The materials used in this study were texts from obtained from corpus reading materials in English consisting of passages in which the researcher's target reading strategies were used deliberately in order to convey a message. The researcher used passages that were more likely to contain large numbers of information learners can mull over and try to reproduce when answering the related comprehension questions.

\subsection{The design}

The Design of this study was a Pre-test Post-test Control Group Design where the subjects were assigned and divided into two groups the experimental group and the control group. The researcher held a treatment for the experimental group which lasted four weeks in the rate of three sessions weekly and each session lasted for 60 minutes. During the experiment, both groups had the same instructor, curriculum, and schedule of instruction. The only difference is that the control group had conventional learning where they dealt with the reading passages without any explicit instruction on using the four techniques used in teaching regarding the reciprocal cognitive method. As for the experimental group, they received explicit instruction on how to read using the reciprocal strategy using the four techniques of predicting, questioning, summarizing and clarifying while maintaining comprehension.

\subsection{The sample}

The sample was taken from the second year at Taif University. The students have taken two terms of English learning as a general topic and are qualified to enter the Foreign Languages Department to specialize in English literature where they earn the bachelor. 32 students were selected, 19 girls and 13 boys who volunteered in the study.

\subsection{Data collection and analysis procedure}

The effectiveness of a metacognitive approach which has been widely described as "thinking about thinking" to teaching reading widely studied at the present time. Its effectiveness on the reading comprehension abilities of readers was the main aim of the researcher. To that end, the experimental subjects received the reading training in order to monitor and understand the specific role of the techniques used to comprehend the passages.

Once the treatment was conducted, the researcher collected the required data by giving a post- test to the control group and the experimental group, By using T-tests, the mean of the two groups were compared with each other in order to establish the following points: was the difference between the mean of the two groups meaningful that the researchers can claim that the gain of the experimental group is attributed to the variable related to the use of the four skills related to the reciprocal techniques of reading while maintaining comprehension.

Figure 1. Table that shows the improvement rate

\begin{tabular}{lllll}
\hline & $\begin{array}{l}\text { Pre-test } \\
\text { Experimental }\end{array}$ & $\begin{array}{l}\text { Post-test } \\
\text { Experimental }\end{array}$ & Pre-test Control & Post-test Control \\
\cline { 2 - 5 } $\mathrm{N}$ & 32 & 32 & 32 & 32 \\
\hline Mean & 9.00 & 13.18 & 8.90 & 10.87 \\
\hline Median & 9.00 & 12.00 & 10.00 & 11.50 \\
\hline Mode & 10.00 & 11.00 & 9.00 & 10.30 \\
\hline Std. Deviation & 2.71 & 3.56 & 2.48 & 3.90 \\
\hline
\end{tabular}




\section{Discussion}

Figure (1) shows that there is a difference in the performance between the two groups, though minimal. It shows one more indication of the students' performance on pretest has improved because of the treatment. The experimental group being versed with one of the metacognitive methods which is the reciprocal reading showed a degree of improvement whereas the control group failed to show improvement over the same three month period. Further the second part of the experiment was to see if the two genders exhibited any differences in regard to their response to the four techniques. Table 2 shows the calculation for the mean, standard deviation, and the significance for the differences as per both sets of scores.

Table 1 T-Test of the effect on the implementation of the reciprocal strategies on Gender

\begin{tabular}{|c|c|c|c|c|c|c|}
\hline Strategy & Gender & $\overline{\mathrm{N}}$ & Mean & Std. Deviation & T-Test & Sig \\
\hline \multirow[t]{3}{*}{ Predicting } & Male & 13 & 5.6000 & 8.41427 & \multirow{3}{*}{-.952} & \multirow{3}{*}{.359} \\
\hline & & & & & & \\
\hline & Female & 19 & 11.0000 & 11.11555 & & \\
\hline \multirow[t]{2}{*}{ Questioning } & Male & 13 & 3.4000 & 5.50424 & \multirow{2}{*}{$-.2 .155$} & \multirow{2}{*}{.051} \\
\hline & Female & 19 & 13.1000 & 9.17061 & & \\
\hline \multirow[t]{2}{*}{ Summarizing } & Male & 13 & 13.4000 & 6.22896 & \multirow{2}{*}{-.609} & \multirow{2}{*}{.553} \\
\hline & Female & 19 & 16.6000 & 13.04011 & & \\
\hline \multirow[t]{2}{*}{ Clarifying } & Male & 13 & 3.4000 & 2.40832 & \multirow{2}{*}{-.519} & \multirow{2}{*}{.612} \\
\hline & Female & 19 & 4.6000 & 4.81202 & & \\
\hline
\end{tabular}

As seen in the table the groups exhibited some differences in their response to the special skills learned as part of the techniques. Both groups have responded positively to all techniques, but the most improvement was recorded in the summarizing techniques as the summaries that were produced were more correct and concise than the ones produced before the application of the techniques.

\section{Limitations of the study and future endeavors}

As Day 1993 and Bamford (1998) indicated in their overview of the number of studies that have been conducted of the impact of intensive reading programs, most of the similar studies have limitation merely because of the amount of time they need to run and the interference of other variables, like maturity and the interference of the other courses the learners are taking. It continues to impact the learning process and be part of the instruction/pedagogy.

Other researchers can explore other dimensions of metacognitive such as the informed strategy for learning, the direct explanation of strategy and the transactional instruction interaction which are parts of the metacognitive comprehension methods of instruction. Further, researchers can apply the methods and study the gender differences as far as the response to the techniques.

\section{Recommendations}

As for the first technique used in the reciprocal training which is predicting and questioning where the students are taught to think aloud, students should be taught that thinking aloud and monitoring the thinking process is known to speed the reading process and increase comprehension. The second set of techniques that should be taught is connecting the text to the already existing knowledge and experiences. This technique can help deepen the understanding of the text. Using the Inferring technique as reading researchers emphasize is another level that can add to the speed and comprehension of the text. That can, in turn be achieved by using experiences and information from the text to draw conclusions, identify connections, make predictions, and form points of views.

The second strategy that is indicated in this research is summarizing. To this end, decisions about what is important in the text have to be made. That enables the students to summarize the main points and use this information to help 
create inferences and that will help in drawing conclusions. Learners should be taught to ask questions about the text before, during, and after reading. Goals and purposes should be set for reading to make it meaningful. Also, students should monitor comprehension and make sure that they have strategies in place if they encounter difficulties.

The third strategy is clarifying. In this strategy the first technique involves using the senses in visualizing and imagining what is being read. Sensory images of the text help to enhance the visualization. Thinking aloud, synthesizing and retelling are also known techniques to enhance comprehension. Students should track their impressions while reading. This technique is useful in identifying the underlying meaning of the text and should be a common practice. Connect the text to information from other sources. Extending that information beyond the text to form opinions and read critically. Text structure and understanding the elements of the texts and how thoughts are put together helps students analyze and think critically about meaning.

\section{References}

Alderson, J. (2000). Reading assessment. New York: Cambridge University Press. http://dx.doi.org/10.1017/CBO9780511732935

Anderson, N. (1999). Exploring second language reading. Boston, MA: Heinle \& Heinle.

Baddeley, A. D. \& Gathercole, S. E. (1992). Learning to read: The role of the phonological loop. In J. Alegria, D. Holender, J. J. de Morais \& M. Radeau (Eds.), Analytic approaches to human cognition, pp 153-168. Amsterdam: Elsevier.

Bereiter, C., \& Bird, M. (1985). Use of thinking aloud in identification and teaching of reading Block, E. L. (1992). See how they Read: Comprehension monitoring of L1 and L2 Readers. TESOL Quarterly 26, 2:319-43.

Bransford, J. (1985). Schema activation and schema acquisition. In H. Singer \& R. B. Ruddell (Eds.), Theoretical models and processes of reading, 3rd ed. Newark, DE: International Reading Association, 385-397.

Brown, A. L. (1987). Metacognition, executive control, self-regulation, and other more mysterious mechanisms. In F. E. Weinert \& R. H. Kluwe (Eds.), Metacognition, motivation, and understanding (pp. 65-116). Hillsdale, NJ: Erlbaum.

Chamot, A. U., \& O'Malley, J. M. (1994). Language learner and learning strategies. In N. C. Ellis (Ed.), Implicit and explicit learning of languages (pp. 371- 392). London: Academic.

Collins, C. (1991). Reading instruction that increases thinking abilities. Journal of Reading, 34, 510-516 (1993) New ways of teaching reading. Washington, DC: TESOL.

Day, R. Bamford, J. (1998). Extensive reading in the second language classroom. New York,NY: Canbridge University Press.

Eskey, D \& Grabe W. (1988). 'Interactive models for second language reading: perspectives on instruction' in Carrell P, Devine J \& Eskey D (Eds.)

Eskey, D. (1988). 'Holding in the bottom: an interactive approach to the language problems of second language readers' in Carrell P. Devine J. \& Eskey D. (Eds).

Flavell, J. H. (1976). Metacognitive aspects of problem solving. In L. B. Resnick (Ed.), The nature of intelligence (pp. 231-235). Hillsdale, NJ: Erlbaum.

Grabe, W., Stoller, F. (2001). Reading and teaching reading. New York: Longman.

Goodman, K.S. (1967). Reading: A psycholinguistic guessing game. Journal of Reading Specialist, 6, 126-35. http://dx.doi.org/10.1080/19388076709556976

Gough, P. B. (1972). One second of reading. In Kavanagh and Mattingley, I. G. (Eds.) Language by ear and by eye. Cambridge, MA: Massachusetts Institute of Technology Press.

Palincsar, A. S. \& Brown, A. L. (1984). Reciprocal teaching of comprehension-fostering and comprehension-monitoring activities. Cognition and Instruction, 1, 117-175. http://dx.doi.org/10.1207/s1532690xci0102_1

Roit, M. L. (1991, December). Teachers using transactional strategy instruction: Three case studies. Paper presented at the annual meeting of the National Reading Conference, Palm Springs, CA. Boston: Heinle \& Heinle.

Rubin, J., \& Thompson, I. (1994). How to be a more successful language learner, 2nd ed. 
Samuels, S.J. \& M.L. Kamil. (1988). "Model of the reading process." Interactive approaches to second language reading. Eds. P.L. Carrell, J. Devine and D.E. Eskey. Cambridge: Cambridge University Press, 1988. 20 (1990 edition).

Smith, C. B. (1988). Strategic thinking in reading. Reading Psychology, 9, 267-274. http://dx.doi.org/10.1080/0270271880090308

Stanovic, K. (2000). Progress in understanding reading: Scientific Foundations and New Frontiers. New York: Guilford.

Stern, H. H. (1975). What can we learn from the good language learner? Canadian Modern Language Review, 31, 304-318.

Urquart, A. H. \& Weir, (1998). Reading in second language. London: Longman. 